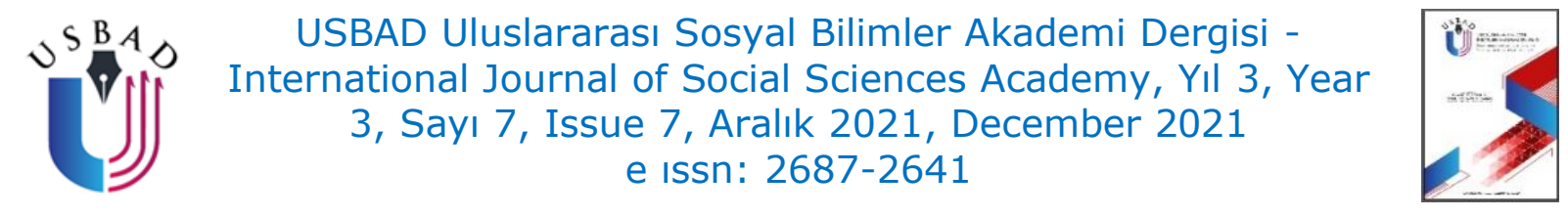

\title{
PANDEMİ SÜRECİNDE ORTAOKUL KIZ ÖĞRENCİLERİN KİŞİSEL VE SOSYAL UYUM DÜZEYLERİ VE OKULU BIRAKMA DURUMLARI
}

\section{PERSONAL AND SOCIAL ADAPTATION LEVELS AND SCHOOL DROPOUT SITUATIONS OF SECONDARY SCHOOL GIRL STUDENTS DURING THE PANDEMIC PROCESS}

\author{
Selma KAHRAMAN \\ Doç. Dr., Harran Üniversitesi, Sağlık \\ Bilimleri Fakültesi \\ Halk Sağlığı Hemşireliği ABD., \\ Şanlıurfa/Türkiye. \\ Assoc. Prof., Harran University, \\ Department of Public Health Nursing, \\ Faculty of Health Sciences, \\ Şanlıurfa/Turkey. \\ skahraman1308@gmail.com \\ ORCID ID: 0000-0002-4486-6629
}

\author{
Suzan HAVLİoĞLU \\ Dr. Öğr. Üy., Harran Üniversitesi, \\ Sağlık Meslek Yüksekokulu, \\ Şanlıurfa/Türkiye. \\ Asst. Prof., Harran University, Health \\ Services Vocational School, \\ Şanlıurfa/Turkey. \\ suzanhavlioglu@hotmail.com \\ ORCID ID: 0000-0001-5593-5688
}

\author{
Makale bilgisi | Article Information \\ DOI: $10.47994 /$ usbad.987014 \\ Makale Türü / Article Type: Araştırma Makalesi / Research Article \\ Geliş Tarihi / Date Received: 25.08.2021 \\ Kabul Tarihi / Date Accepted: 17.12.2021 \\ Yayın Tarihi / Date Published: 20.12.2021 \\ Yayın Sezonu / Pub Date Season: Aralık / December
}

Bu Makaleye Atıf İçin / To Cite This Article: Kahraman, S. \& Havlioğlu, S. (2021). Pandemi Sürecinde Ortaokul Kız Öğrencilerin Kişisel ve Sosyal Uyum Düzeyleri ve Okulu

Bırakma Durumları. USBAD Uluslararası Sosyal Bilimler Akademi Dergisi 3(7), 18211834.

Intihal: Bu makale intihal.net yazılımınca taranmıştır. İntihal tespit edilmemiştir.

Plagiarism: This article has been scanned by intihal.net. No plagiarism detected.

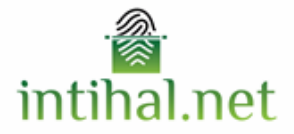

İletişim: Web: https://dergipark.org.tr/tr/pub/usbad mail: usbaddergi@gmail.com 
Öz: Bu araştırma pandemi sürecinde ortaokullarda öğrenin gören kız öğrencilerin kişisel ve sosyal uyum düzeyleri ve okulu bırakma durumlarını belirlemek amacıyla kesitsel tanımlayıcı olarak yapılmıştır. Araştırmanın örneklemini Şanlıurfa ilinde sosyal ve ekonomik olarak dezavantajlı sayılan 3 köy okulunda bulunan $94 \mathrm{kIz}$ öğrenci oluşturmuştur. Bu araştırmada Hacettepe Kişilik Envanteri (HKE) kullanılmışır. Verilerin değerlendirilmesi SPSS 22.0 programında tanımlayıcı istatistik ve sürekli değişkenler yönünden farkın önemliliği bağımsız gruplarda $t$ testi ve F-testi (tek yönlü ANOVA) ile araştırımıştır. Bu çalışmada kız öğrencilerin $\% 59,6$ 'sı uzaktan eğitimde derslere katılmadığını, \%5,3'ü ise pandemi sürecinde okulu bıraktığı görülmüştür. Kız öğrencilerin toplam uyum puan ortalamaları $73,91 \pm 19,56$ olduğu, bu puanın düşük olduğu görülmüştür. Kız öğrencilerin sosyal uyum puanı ve kişisel uyum puan ortalamasının düşük olması, sosyal ve kişisel olarak uyumlu olmadığı saptanmıştır. HKE normlarına göre tedavi edici ruh sağlığı uygulamalarına alınması gereken, \%25 yüzdelik dilimin karşılı̆̆ olan genel uyumda 70 , sosyal uyumda 40 , kişisel uyumda 30 ve altında puan alan öğrenciler değerlendirildiğinde; araştırmaya katılan kız öğrencilerin sosyal uyum puan ortalamalarının tedavi edici ruh sağlığı uygulamalarına alınması gereken puanda olduğu görülmüştür.

Anahtar Kelimeler: Pandemi, Kız Öğrenci, Kişisel/Sosyal Uyum, Okul, Sağlık

Abstract: This research was conducted as a cross-sectional descriptive study in order to determine the personal and social adjustment levels and dropout status Sayfa | 1822 of secondary school female students during the pandemic process. The sample of the study consisted of 94 female students in 3 village schools in Şanlıurfa province, which are considered to be socially and economically disadvantaged. Hacettepe Personality Inventory ( $\mathrm{HCI}$ ) was used in this study. Evaluation of the data The significance of the difference in terms of descriptive statistics and continuous variables in SPSS 22.0 program was investigated with independent samples t-test and F-test (One way ANOVA). A p value below 0.05 was considered significant for all analyses. In this study, it was seen that $59.6 \%$ of female students did not attend distance education classes, and 5.3\% dropped out of school during the pandemic period. It was observed that the total mean score of adjustment of female students was 73.91 19.56 , and this score was lower. The mean score of social cohesion and mean score of personal adjustment of the female students were lower, it was determined that they were not socially and personally compatible. When the students who should be included in the therapeutic mental health practices according to $\mathrm{HCI}$ norms, who score 70 in general adjustment, 40 in social adjustment, and 30 and below in personal adjustment, which corresponds to the $25 \%$ percentile, were evaluated, It was seen that the mean score of social adjustment of female students participating in the study was at the point that should be taken into therapeutic mental health practices.

Key Words: Pandemic, Girl Students, Personal/Social Adaptation, School, Health 


\section{GİRİŞ}

İlk kez Aralık 2019'da tespit edilen ve tüm dünyaya yayılan yeni koronavirüs hastalığı (Covid-19) ciddi bir halk sağlığı sorunu olarak küresel etkisini devam ettirmektedir. Dünya Sağlık Örgütü'nün (WHO) pandemi ilanıyla birlikte Covid-19 etkeni kıtalar arası milyonlarca insanı etkileyerek, duyarlı kişilerde ölüme neden olmuştur (Arı ve Duman, 2020; Hacettepe İç Hastalıkları Derneği, 2021; Khoury ve Karam, 2020). Pandemiler bireyi ve toplumu sosyolojik, psikolojik gibi birçok düzeyde etkileyen ve bozulmalara neden olan sosyal bir olgudur. Çünkü insanlar bulaşıcı hastalığın kendisine vereceğini zarar algısı arttıkça panik ve stres daha fazla yaşamakta ve daha farklı davranışlar sergilemektedirler. Dünyanın dört bir yanındaki hükümetlerin çoğu, Covid-19 salgınının yayılmasını önlemek amacıyla eğitim kurumlarında yüz yüze eğitime geçici olarak ara vermiş ve uzaktan eğitime geçmiştir (Karataş, 2020; Sarı ve Nayır, 2020; Yıldırım, 2020). Ülke çapındaki bu kapanışlar UNESCO'nun 1 Mart 2021 verilerine göre 144.697.476 öğrenciyi etkilemiştir (UNESCO, 2021).

Uzaktan eğitim, kendine özgü düzenlemeler ve öğretme teknikleri gerektiren elektronik olsun ya da olmasın farklı ortamlarda gerçekleştirilen öğrenme şeklidir. Bu eğitimin avantajları; zaman ve mekândan bağımsız bir şekilde eğitimin verilebilmesi, bir dersin tekrar tekrar izlenebiliyor olması, Sayfa | 1823 teknolojinin eğitim içeriklerinde önemli bir yer alması ve bu konuda öğrencilerde beceri geliştirilmesi olarak sayılabilir (Dede vd., 2021; Erdem ve Arı, 2021; Karataş, 2020). Dezavantajları ise; motivasyon düşüklüğü, ölçme ve değerlendirme zorluğu, bilgisayar ve internet gibi gerekli alt yapının yetersizliği, eğitimde fırsat eşitsizliğine neden olabilmesi, etkileşim ve iletişimde yetersizlik oluşturması, sosyalleşmede yaşanan sorunlardır (Dede vd., 2021; Kaynar vd., 2020; Sarı ve Nayır, 2020; Yakut, 2020; Yıldırım, 2020). Pandemi döneminde eğitimde yaşanan olumsuzluklar arasında sayılabilecek durumlar özetlendiğinde, öğrenme kaybı ve okulu bırakma oranlarının artması başta gelmektedir (Dede vd., 2021; Erdem ve Arı, 2021; Karataş, 2020; Kaynar vd., 2020; Sarı ve Nayır, 2020; Yakut, 2020; Yıldırım, 2020).

Ülkemizin birçok yöresinde özellikle Şanlıurfa'da kız çocuklarda okullaşma oranı çok düşüktür. Bu yüzden UNICEF eğitim hakkından yoksun kalan çocuklar arasında kız çocuklar üzerine odaklanılarak tüm çocuklar için kaliteli eğitime erişim için çabaların artırılmasının ve kız çocuklarını okula devam etmekten ve okulda başarı göstermekten alıkoyan tüm engellerin sistematik biçimde ortadan kaldırılmasının gerekliliğini vurgulamaktadır 
(Adıgüzel, 2013). Bu nedenle Covid-19 salgınının ve uzaktan eğitimin kız öğrencileri daha fazla olumsuz etkilediğini düşündürmektedir.

Öğrenme sorumluluğunun büyük bir kısmını öğrenciye veren uzaktan eğitim sürecinde yaşanan derse girmeme, dersi yarıda bırakma, motivasyon kaybı gibi öğrenci kaynaklı sorunların ve uyum düzeylerinin incelenmesi önem arz etmektedir. Ergen olarak kabul edilen ortaokul dönemi öğrencilerinin ruhsal, zihinsel, motor ve sosyal becerilerini kazanmalarını sağlayan faktörler akran grupları ve okuldur (Adıgüzel, 2013; Kalyencioğlu ve Kutlu, 2010; Kaynar vd., 2020). Bu doğrultuda Covid-19 salgını süreci içerisinde ortaokul kız öğrencilerinin psikolojik, sosyolojik ve duygusal uyum düzeylerinin ve okulu bırakma durumlarının araştırılması gerekmektedir (Alıcılar vd., 2020; Baykal, 2020; Dede vd., 2021; Erdem ve Arı, 2021; Kaynar vd., 2020). Ayrıca kız öğrencilerin bu sürece uyum durumlarının bilimsel yöntemlerle belirlenmesi bu konuda bilgi eksikliğini giderecek ve olası bir durum için yine birçok afette olduğu gibi hazırlıklı olunmasını sağlayacaktır. Bu çerçevede bu araştırma pandemi sürecinde ortaokul kız öğrencilerin kişisel ve sosyal uyum düzeyleri ve okulu bırakma durumlarını belirlemek amacıyla yapılmıştır.

\section{GEREÇ VE YÖNTEM}

Araştırmanın tipi: Bu araştırma pandemi sürecinde ortaokullarda öğrenim gören kız öğrencilerin kişisel ve sosyal uyum düzeyleri ve okulu bırakma durumlarını belirlemek amacıyla kesitsel tanımlayıcı olarak yapılmıştır.

Evren ve Örneklem: Araştırmanın evrenini Girls in Action-Covid Response Team adlı proje kapsamında olan Şanlıurfa ilinde sosyal ve ekonomik olarak dezavantajlı sayılan 3 köy okulunda bulunan kız öğrencileri oluşturmaktadır. Araştırmada örnekleme yöntemine gidilmemiş olup, proje kapsamında ulaşılan ve araştırmayı kabul eden 94 kız öğrenci örneklem grubuna dahil edilmiştir. Öğrencilere uzaktan eğitim dersleri sırasında ulaşılmış, araştırma hakkında bilgi verilerek sözel onam alınmış ve anketler öğrencilere öğretmenleri vasıtasıyla ulaştırılmıştır. Ulaşılan kız öğrenci 152 'dir. Öğrencilerin 22'si araştırmaya katılmayı kabul etmemiş, 36 öğrenci veri toplama araçlarına eksik yanıt vermiş veya yanıtlamadığından veri analizine dahil edilmemiştir.

Veri Toplama Araçları: Bu araştırmada Hacettepe Kişilik Envanteri (HKE) kullanılmıştır. Hacettepe Kişilik Envanteri, bireyin kişisel ve sosyal uyum düzeylerini ölçen ve "Kişisel Uyum" ve "Sosyal Uyum" olmak üzere iki temel bölüm ile sekiz alt ölçekten ve toplam 168 maddeden meydana 
gelmiştir. HKE "Kişisel Uyum" (Kendini Gerçekleştirme (KG), Duygusal Kararlılık (DK), Nevrotik Eğilimler (NE), Psikotik Belirtiler (PB)için dört ve "Sosyal Uyum" (Aile İlişkileri (AI), Sosyal ilişkiler (Sİ), Sosyal Normlar (SN), Antisosyal Eğilimler (AE)için dört olmak üzere 8 alt gruptan oluşmuştur. "Kişisel Uyum" ve "Sosyal Uyum" puanlarının toplamı "Genel Uyum" puanını oluşturmaktadır. Çalışmada ölçeğin iç tutarlılık katsayısı 0.86 bulunmuş olup, ölçek geçerli ve güvenilirdir (Özgüven, 1992). Bu araştırmada iç tutarlılık katsayısı 0,91 olarak hesaplanmıştır.

\section{Etik Onay ve İzinler}

Araştırma öncesi Sağlık Bakanlığı́nın Bilimsel Araştırma Platformuna (2021-03-30T11_56_20.) yapılan online başvuru ile gerekli çalışma izni, Harran Üniversitesi Klinik Araştırmalar Etik Kurulu'ndan da etik izin (Karar No: 24.05.2021/10) ve İl Milli Eğitim Müdürlüğünden gerekli izinler alınmıştır.

\section{İstatistiksel Analiz}

Elde edilen veriler SPSS 22.0 ile analiz edilmiştir. İstatistiksel analizlerde sürekli değişkenler için ortalama, standart sapma, minimum ve maksimum değerler; nominal değişkenler için sayı ve yüzde kullanılmıştır. Sürekli değişkenlerin normal dağılıma uygunlukları, normal dağılım Sayfa| 1825 grafikleri, çarpıklık ve basıklık katsayı değerleri birlikte incelenerek belirlenmiştir. Sürekli değişkenler yönünden farkın önemliliği bağımsız gruplarda $\mathrm{t}$ testi ve F-testi (tek yönlü ANOVA) ile araştırılmıştır. Tüm analizler için 0,05'in altındaki $\mathrm{p}$ değeri anlamlı kabul edilmiştir.

\section{Bulgular}

Bu araştırmaya katılan kız öğrencilerin $\% 60,6$ 'sının 12 yaş ve üstü

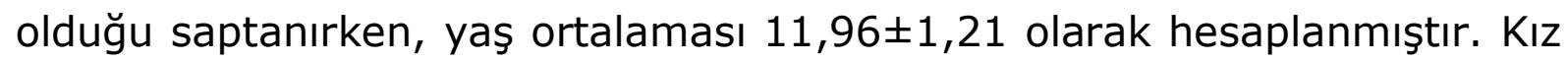
öğrenci annelerinin \%47,9'unun okuryazar olmadığı, babalarının ise $\% 58,5$ 'inin ilkokul veya daha üstü eğitime sahip olduğu görülmüştür. Öğrencilerin \%58,5'inin aile üye sayısı 3-8 kişiliktir. Kız öğrencilerinin $\% 57,4$ 'ünün aile gelirlerinin giderlerine eşit olduğunu ifade etmiştir.

Kız öğrencilerin \%14,9'u ailesinden birinin Covid-19 hastalığı geçirdiğini belirtmiştir. Öğrencilerin \%59,6'sı uzaktan eğitim derslerine katılmadıklarını; katılmama nedenleri olarak \%54,8'i tablet, telefon ve bilgisayar, \%31,0'ı internet olmamasından dolayı olduğu söylenmiştir. Kız öğrencilerin \%5,3'ü pandemi sürecinde okulu bıraktığını ifade etmiştir.

Tablo 1: Öğrencilerin Hacettepe Kişilik Envanterine Göre Kişilik, Sosyal, Genel ve Alt Boyutları Uyum Puanlarına İlişkin İstatistiki Değerler 


\begin{tabular}{|c|c|c|c|c|c|c|}
\hline & $\mathrm{N}$ & $\overline{\mathrm{x}}$ & Ss & Min & Max & $\begin{array}{l}\text { Tam } \\
\text { Değer }\end{array}$ \\
\hline Genel Uyum Puanı & 94 & 73,91 & 19,56 & 11 & 124 & 160 \\
\hline Kişisel Uyum Puanı & 94 & 36,77 & 10,64 & 6 & 66 & 80 \\
\hline Sosyal Uyum Puanı & 94 & 37,13 & 10,07 & 5 & 58 & 80 \\
\hline Kendini Gerçekleştirme & 94 & 9,39 & 3,08 & 1 & 19 & 20 \\
\hline Duygusal Kararlılık & 94 & 9,14 & 2,87 & 2 & 16 & 20 \\
\hline Nevrotik Eğilimler & 94 & 8,83 & 3,53 & 1 & 17 & 20 \\
\hline Psikotik Belirtiler & 94 & 9,41 & 3,33 & 2 & 18 & 20 \\
\hline Aile İlişkileri & 94 & 8,96 & 2,98 & 2 & 16 & 20 \\
\hline Sosyal ilişkiler & 94 & 9,70 & 3,12 & 2 & 17 & 20 \\
\hline Sosyal Normlar & 94 & 9,66 & 2,80 & 0 & 16 & 20 \\
\hline Anti Sosyal Eğilimler & 94 & 8,82 & 3,47 & 0 & 18 & 20 \\
\hline
\end{tabular}

Tablo 1'e göre kız öğrencilerin toplam uyum puan ortalamalarının $73,91 \pm 19,56$ olduğu, bu puanın 0-160 puan aralığının orta noktası olan 80 puandan düşük olduğu görülmüştür. Kız öğrencilerin sosyal uyum puanı ortalaması $(37,13)$ ve kişisel uyum puan ortalaması $(36,13)$, 0-80 puan Sayfa | 1826 aralığının orta noktası olan 40 puandan düşük olduğu için sosyal ve kişisel olarak uyumlu olmadığı saptanmıştır.

HKE normlarına göre tedavi edici ruh sağlığı uygulamalarına alınması gereken, \%25 yüzdelik dilimin karşılığı olan genel uyumda 70 , sosyal uyumda 40, kişisel uyumda 30 ve altında puan alan öğrenciler değerlendirildiğinde kız öğrencilerinin sosyal uyum puan ortalamalarının bu düzeyde olduğu görülmüştür. Alt boyutların hepsinin puanı ortalaması ise \%50 dilime karşılık gelmektedir.

Tablo 2: Öğrencilerin Sosyo-Demografik Özelliklerine Göre Genel, Kişilik ve Sosyal Uyum Puan Ortalamaları

\begin{tabular}{llll}
\hline Değişkenler & $\begin{array}{l}\text { Genel Uyum } \\
\bar{X} \pm \text { SS }\end{array}$ & $\begin{array}{l}\text { Kişisel Uyum } \\
\bar{X} \pm \text { SS }\end{array}$ & $\begin{array}{l}\text { Sosyal Uyum } \\
\bar{X} \pm S S\end{array}$ \\
\hline Yaş & & & \\
12 yaş altı & $76,4 \pm 22,1$ & $38,2 \pm 11,3$ & $38,2 \pm 12,4$ \\
12 yaş ve üstü & $72,2 \pm 17,7$ & $35,8 \pm 10,1$ & $36,4 \pm 8,5$ \\
$t$ & 1,016 & 1,057 & 0,856 \\
$\mathrm{p}$ & 0,312 & 0,293 & 0,394 \\
\hline Anne Eğitim Durumu & & & \\
Okuryazar Değil & $77,6 \pm 18,8$ & $39,2 \pm 9,7$ & $38,4 \pm 10,2$ \\
& $70,4 \pm 19,7$ & $34,5 \pm 11,0$ & $35,8 \pm 9,8$ \\
\hline
\end{tabular}


Selma Kahraman - Suzan Havlioğlu

\begin{tabular}{llll}
\hline $\begin{array}{l}\text { Okuryazar ve daha üstü } \\
\mathrm{t}\end{array}$ & 1,814 & 2,157 & 1,250 \\
$\mathrm{p}$ & 0,073 & 0,034 & 0,215 \\
\hline Uzaktan Eğitime Katılma Durumu & & & \\
Evet & $76,18 \pm 21,4$ & $38,1 \pm 11,5$ & $38,0 \pm 11,1$ \\
Hayır & $72,3 \pm 18,2$ & $35,8 \pm 9,9$ & $36,5 \pm 9,3$ \\
$\mathrm{t}$ & 0,926 & 1,057 & 0,681 \\
$\mathrm{p}$ & 0,357 & 0,293 & 0497 \\
\hline Pandemi Sürecinde Okulu Bırakma & & & \\
Durumu & $64,6 \pm 34,0$ & $33,2 \pm 15,4$ & $31,4 \pm 18,8$ \\
Evet & $74,4 \pm 18,6$ & $-0,770$ & $37,4 \pm 9,4$ \\
Hayır & $-1,095$ & 0,443 & $-1,314$ \\
$\mathrm{t}$ & 0,276 & & 0,192 \\
$\mathrm{p}$ & & & \\
\hline
\end{tabular}

Tablo 2'de verilen bilgilere göre 12 yaş ve üstü kız öğrencilerin genel, sosyal ve kişisel uyum puanlarının 12 yaş altına göre daha düşüktür. Yaş ile uyum puanları arasında istatistiksel fark anlamlı değildir ( $p>0.05)$.

Uzaktan eğitime katıldığını ifade eden kız öğrencilerin genel, sosyal ve kişisel uyum puan ortalamaları katılmayanlara göre daha yüksektir $(p>0.05)$. Pandemi sürecinde okulu bırakmadığını belirten öğrencilerin de genel, sosyal ve kişisel uyum puan ortalamaları bırakan öğrencilere göre ${ }_{\text {Sayfa | } 1827}$ daha yüksektir. Bu iki değişken arasında istatistiksel fark anlamlı değildir $(p>0.05)$.

Annelerinin okuryazar olmadığını belirten öğrencilerin kişisel uyum puan ortalaması 39,2 $\pm 9,7$ iken, anneleri okuryazar yâda daha üstü eğitime sahip olan kız öğrencilerin puan ortalaması $34,5 \pm 11,0$ olarak hesaplanmış ve bu değişkenler arasında istatistiksel fark anlamlı çıkmıştır $(p<0,05)$.

\section{Tartışma}

Bu çalışma, kız çocukların eğitim durumunda dezavantajlı olarak en belirgin görüldüğü ilde yapılması, uzaktan eğitimin kız çocukları üzerinde etkisini ortaya çıkarması açısından önemlidir. Ayrıca bu çalışma pandemi sürecinde kız çocuklarının uyum durumları ve okulu bırakma durumunu irdeleyen ilk çalışmadır. Ülkemizin kız çocuklarında düşük okullaşma oranları, okur-yazar olmayan kadınların bebek ve anne ölüm oranlarının yüksekliği gibi temel göstergelerden de görülebileceği gibi, bu durum hem çocuğun gelişimi ve eğitimi hem de toplumun geleceği üzerinde olumsuz etki yaratabileceği (Adıgüzel, 2013; Erdem ve Arı, 2021) düşüncesiyle bu konudaki çalışmaların öncelikli alınması önemlidir. 
Bu çalışmada ortaokula giden kız öğrencilerin kişisel, sosyal uyum puan ortalamasını düşük çıkması öğrencilerin sosyal ve kişisel olarak uyumlu olmadıklarını göstermiştir. Ayrıca öğrencilerin sosyal uyum puan ortalamaların 40 puanın altında olması tedavi edici ruh sağığı uygulamalarına alınması gerektiğini göstermektedir. Bu konuda yapılan çalışmalar olmadığı için kıyaslama yapılmamakla beraber aynı envanteri kullanan kız öğrencilerin çoğunlukta olduğu bir araştırmada öğrencilerin aldığı genel uyum puanı $100,29 \pm 18,67$ olarak hesaplanmış ve bu puanın $\% 75,0$ 'lık dilimden daha yukarda olduğu görülmüştür (Kalyencioğlu ve Kutlu, 2010). Bu sonuç, kız öğrencilerin uzaktan eğitimle değişen bu duruma uyum sağlayamadıklarını, pandemi sürecinin gerektirdiği davranış biçimlerini benimsemediğini özellikle sosyal uyum durumlarının daha kötüye gittiğini düşündürebilir.

Bu çalışma sonucunu destekler biçimde yapılan bir araştırmada; kız öğrencilerin uzaktan eğitime ilişkin genel puanları, düşünceleri, tutumları ve öğretim alt boyutu ile ilgili puanları erkek öğrencilerin puanlarından daha düşük bulunmuştur (Kaynar vd., 2020). Başka bir çalışmada ise kIz öğrencilerin pandemi sürecinde, kişisel bakım ve temizliğe dikkat etme, kurallara uyma ve uymayanları uyarma, aile üyeleriyle (anne, baba, kardeş) sorun yaşama sıklığı ve okula gitme isteği" konularında "arttı" seçeneği üzerinden, "çevrimiçi (online) derslerde öğrenme düzeyi" konusunda da "azaldı" seçeneği üzerinden anlamlı fark oluşturdukları görülmektedir (Yakut, 2020).

$\mathrm{Bu}$ araştırmada istatistiksel olarak anlamlı bir fark olmasa da 12 yaş altının, uzaktan eğitime katıldığını ve okulu bırakmadığını ifade eden kız öğrencilerin genel, sosyal ve kişisel uyum puan ortalamaları daha yüksek bulunmuştur $(p>0.05)$. Bu sonuçlar okulu bırakmanın ya da derslere uzaktan bile olsa katılmanın kişisel ve sosyal uyuma etkisinin olumlu olduğunu gösterecek araştırmacılara ihtiyaç olduğunu göstermektedir. Ayrıca anneleri okuryazar olmayan kız öğrencilerin kişisel uyum puanlarının anlamlı olarak yüksek olması düşündürücü bir faktördür $(p<0,05)$.

Bu çalışmada kız öğrencilerin \%59,6'sı uzaktan eğitim derslerine katılmadığını belirtmiştir. Okul devamsızlığı büyük bir sorundur. Milli Eğitim Bakanlığı (MEB), okul devamsızlığının en yüksek olduğu illeri tespit etmek ve devamsızlık nedenlerini ortaya çıkarmak için birkaç çalışmalar yapmış ve rapor hazırlamıştır. MEB'in 2019 Yılı göre; ortaokullarda 20 gün ve üzeri devamsızlık yapan öğrencilerin oranı da yüzde 9,98'den yüzde 9,90'a düşmüştür. Milli Eğitim Bakanlığı'nın 2020 Küresel Salgın Döneminde 
Uzaktan Eğitim İzleme ve Değerlendirme Raporuna göre uzaktan eğitim sürecinde EBA üzerinden gerçekleştirilen çevrim içi derslere katılma durumuna bakıldığında öğrencilerin \%76'sı canlı derslere katıldığını, \%24'ü ise canlı derslere katılmadıklarını belirtmişlerdir (Erdem ve Arı, 2021). Oysa bu çalışmada derse katılmama oranının oldukça yüksek olması bu durumu yakından takip edilmesi teşvik edici noktaların yapılması gerektiğini düşündürmektedir.

\section{SONUÇ VE ÖNERİLER}

$\mathrm{Bu}$ çalışmada pandemi sürecinde ortaokula giden kız öğrencilerin sosyal ve kişisel olarak uyumlu olmadığı ve öğrencilerin sosyal uyum düzeylerinin tedavi edici ruh sağlığı uygulamalarına alınması gerektiği saptanmıştır. Bu çalışmada kız öğrencilerin \%59,6'sının uzaktan eğitim derslerine katılmadığı, \%5,3'ü ise pandemi sürecinde okulu bıraktığı tespit edilmiştir. Bu sonuçlar doğrultusunda;

- Pandemi süreciyle birlikte hayatımıza yoğun olarak giren uzaktan eğitimin özellikle kız öğrencilerinde etkili ve verimli değerlendirilmesi için araştırmalar artırılmalıdır,

- Çevrim içi derslere devamsızlık nedenlerinin tespit edilmesi kadar bu devamsızlık durumuna neden olan etkenlerin giderilmesi için Sayfa| 1829 programlar yapılmalıdır,

- Kız öğrencilerin hem kişisel hem de sosyal uyum durumunu etkileyen faktörlerin belirlenmesi, irdelenmesi ve önlemeye yönelik uygulamaların artırılması gerekmektedir.

\section{KAYNAKÇA}

Adıgüzel, A. (2013). Kız Çocuklarının Okullaşma Engelleri ve Çözüm Önerileri (Şanlıurfa Örneği). Ekev Akademi Dergisi 17(56), 325-345.

Alıcılar, H. E. vd. (2020). Toplumda Covid-19 Pandemisiyle İlgili Farkındalık, Tutum ve Davranışların Değerlendirilmesi. Estüdam Halk Sağlı̆̆ı Dergisi 5, $1-16$.

Arı, M. \& Duman, T. (2020). COVID-19 and Mental Health. Duzce Med J 22(1), 19-22.

Baykal, E. (2020). Covıd-19 Bağlamında Psikolojik Dayanıklılık, Kaygı ve Yaşam Doyum İlişkisi. International Journal of Social and Economic Sciences 10(2), 68-80.

Dede, N. vd. (2021). Covid-19 Süreci ile Başlayan Uzaktan Eğitimde Ortaokul Öğrencilerinin Öz Düzenleme ve Derse Katılım İlişkisinin 
İncelenmesi. Dicle Üniversitesi Ziya Gökalp Eğitim Fakültesi Dergisi 39, 126134.

Erdem, S. \& Arı, A. G. (2021). Çevrim İçi Eğitimde Öğrencilerin Devamsızlık Nedenlerinin Araştırılması. Sosyal Bilimler ve Eğitim Dergisi (JOSSE) 4(1), 57- 79.

Hacettepe İç Hastalıkları Derneği. (Ed.). İskit, A. T., Tanrıöver, M. D. \& Uzun, Ö. Covid-19 Pandemi Raporu (20 Mart-20 Kasım 2020). Ocak. 2021. Hamza, A. (2007). Bilimsel Araştırma Yöntemleri, Akademik Yazım Kuralları. Sakarya: Sakarya Yayıncılık.

Kalyencıoğlu, D \& Kutlu, Y. (2010). Ergenlerin Aile İşlevi Algılarına Göre Uyum Düzeyleri. İ.Ü.F.N. Hem Dergisi 18(2), 56-62.

Karataş, Z. (2020). Covıd-19 Pandemisinin Toplumsal Etkileri, Değişim ve Güçlenme. Türkiye Sosyal Hizmet Araştırmaları Dergisi 4(1), 3-15

Kaynar, H. vd. (2020). Ortaokul Öğrencilerinin Uzaktan Eğitime İlişkin Görüşleri. Turkish Studies 15(7), 3269-3292.

Khoury R. \& Karam G. (2020). Impact of COVID-19 On Mental Health Care of Older Adults: In Sights From Lebanon (Middle East). International Psychogeriatrics 24, 1-4.

Özgüven İ. E. (1992). Hacettepe Kişilik Envanteri El Kitabı. İkinci Revizyon. Ankara, 1-62.

Sarı T. ve Nayır F. (2020). Pandemi Dönemi Eğitim: Sorunlar ve Fırsatlar. Turkish Studies 15(4), 959-975.

UNESCO. (Birleşmiş Milletler Eğitim, Bilim ve Kültür Örgütü). COVID-19'un Eğitime Etkisi. Erişim Adresi: https://en.unesco.org/covid19/educationresponse. Erişim Tarihi: 01.07.2021.

Yakut, S. (2020). Pandemi Sürecinin Lise Öğrencileri Üzerindeki Psikososyal Etkilerinin İncelenmesi. Journal of Social and Humanities Sciences Research $7(58), 2334-2347$.

Yıldırım, S. (2020). Salgınların Sosyal-Psikolojik Görünümü: Covid-19 (Koronavirüs) Pandemi Örneği. Electronic Turkish Studies 15(4), 13311351.

GENIŞ̧LETímíş ÖZET: İlk kez Aralık 2019'da tespit edilen ve tüm dünyaya yayılan yeni koronavirüs hastalı̆ı (Covid-19) ciddi bir halk sağlığı sorunu olarak küresel etkisini devam ettirmektedir. Pandemiler tıbbi bir fenomen olmanın yanında bireyi ve toplumu birçok düzeyde etkileyen ve bozulmalara neden olan sosyal bir olgudur. Çünkü bulaşıcı hastalığın ortaya çıkardığı tehdit algısı arttıkça 
panik ve stres yaşayan insanlar, her zaman olduğundan daha farklı davranışlar sergilemektedirler. Dünyanın dört bir yanındaki hükümetlerin çoğu, Covid-19 salgınının yayılmasını önlemek amacıyla eğitim kurumlarında yüz yüze eğitime geçici olarak ara vermiş ve uzaktan eğitime geçmiştir. Pandemi döneminde eğitimde yaşanan olumsuzluklar arasında sayılabilecek durumlar özetlendiğinde, öğrenme kaybı ve okulu bırakma oranlarının artması başta gelmektedir. Ülkemizin birçok yöresinde özellikle Şanlıurfa'da kız çocuklarda okullaşma oranı çok düşüktür. Bu yüzden UNİCEF eğitim hakkından yoksun kalan çocuklar arasında kız çocuklar üzerine odaklanılarak tüm çocuklar için kaliteli eğitime erişim için çabaların artırılması ve kız çocuklarını okula devam etmekten ve okulda başarı göstermekten alıkoyan tüm engellerin sistematik biçimde ortadan kaldırılmasını gerektiğini vurgulamaktadır (Adıgüzel, 2013). Bu nedenle Covid-19 salgını ve uzaktan eğitim kız öğrencilerini daha fazla olumsuz etkilediğini düşündürmektedir. Bu çerçevede bu araştırma pandemi sürecinde ortaokul kız öğrencilerin kişisel ve sosyal uyum düzeyleri ve okulu bırakma durumlarını belirlemek amacıyla yapılmıştır. Kesitsel tanımlayıcı bir araştırmadır. Kesitsel tanımlayıcı yapılan bu araştırmanın evrenini Girls in Action- Covid Response Team adlı proje kapsamında olan Şanlıurfa ilinde sosyal ve ekonomik olarak dezavantajlı sayılan 3 köy okulunda bulunan kız öğrencileri oluşturmaktadır. Araştırmada örnekleme yöntemine gidilmemiş olup, proje kapsamında ulaşılan ve araştırmayı kabul eden 94 kız öğrenci örneklem grubuna dahil edilmiştir. Öğrencilere uzaktan eğitim dersleri sırasında ulaşılmış, araştırma hakkında bilgi verilerek sözel onam alınmış veSayfa|1831 anketler öğrencilere öğretmenleri vasıtasıyla ulaştırılmıştır. Bu araştırmanın verilerini Hacettepe Kişilik Envanteri (HKE) kullanılarak toplanmıştır. Araştırma öncesi Sağlık Bakanlığı'nın Bilimsel Araştırma Platformuna (2021-0330T11_56_20.) yapılan online başvuru ile gerekli çalışma izni, Harran Üniversitesi Klinik Araştırmalar Etik Kurulu'ndan da etik izin (Karar No: 24.05.2021/10) alınmıştır. Elde edilen veriler IBM SPSS Statistics v.22.0 paket programına kaydedilerek değerlendirilmiştir. İstatistiksel analizlerde sürekli değişkenler için ortalama, standart sapma, minimum maksimum değerler; nominal değişkenler için sayı ve yüzde kullanılmıştır. Sürekli değişkenlerin normal dağııma uygunlukları Shapiro-Wilk testi, normal dağılım grafikleri, çarpıklık ve basıklık katsayı değerleri birlikte incelerek belirlenmiştir. Sürekli değişkenler yönünden farkın önemliliği bağımsız gruplarda $t$ testi ve F-testi (tek yönlü ANOVA) ile araştırılmıştır. Tüm analizler için 0,05'in altındaki $\mathrm{p}$ değeri anlamlı kabul edilmiştir. Bu araştırmaya katılan kız öğrencilerin \%60,6'sının 12 yaş ve üstü olduğu saptanırken, yaş

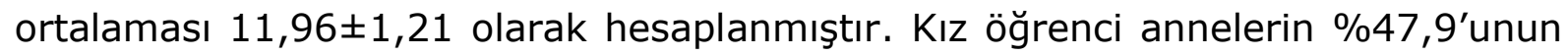
okuryazar olmadığı, babalarının ise $\% 58,5$ 'inin ilkokul veya daha üstü eğitime sahip olduğu görülmüştür. Öğrencilerin \%58,5'i aile üye sayısı 3-8 kişiliktir. Kız öğrencilerinin \%57,4'ünün aile gelirlerinin gidere eşit olduğunu ifade etmiştir. Kız öğrencilerin \%14,9'u ailesinden birinin covid-19 hastalığı geçirdiğini belirtmiştir. Öğrencilerin \%59,6'sı uzaktan eğitim derslere katılmadıklarını; katılmama nedenleri olarak \%54,8'i tablet, telefon, bilgisayar, \%31,0'ו internet olmamasından 
dolayı olduğu söylemiştir. Kız öğrencilerin \%5,3'ü pandemi sürecinde okulu bıraktığını ifade etmiştir. Kız öğrencilerin HKE toplam uyum puan ortalamaları

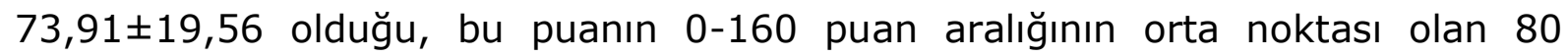
puandan düşük olduğu görülmüştür. Kız öğrencilerin sosyal uyum puanı ortalaması $(37,13)$ ve kişisel uyum puan ortalaması $(36,13), 0-80$ puan aralığının orta noktası olan 40 puandan düşük olduğu için sosyal ve kişisel olarak uyumlu olmadığı saptanmıştır. HKE normlarına göre tedavi edici ruh sağlığı uygulamalarına alınması gereken, \%25 yüzdelik dilimin karşılığı olan genel uyumda 70, sosyal uyumda 40, kişisel uyumda 30 ve altında puan alan öğrenciler değerlendirildiğinde kız öğrencilerinin sosyal uyum puan ortalamalarının bu düzeyde olduğu görülmüştür. Alt boyutların hepsinin puanı ortalaması ise \%50 dilime karşılık gelmektedir. Annelerinin okur-yazar olmadığını belirten öğrencilerin kişisel uyum puan

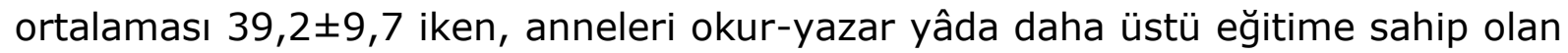
kızların puan ortalaması 34,5 $\pm 11,0$ olarak hesaplanmış ve bu değişkenler arasında istatistiksel fark anlamlı çıkmıştır $(p<0,05)$. Bu çalışmada pandemi sürecinde ortaokula giden kız öğrencilerin sosyal ve kişisel olarak uyumlu olmadığı ve öğrencilerin sosyal uyum düzeylerinin tedavi edici ruh sağlığı uygulamalarına alınması gerektiği saptanmıştır. Bu çalışmada kız öğrencilerin \%59,6'sının uzaktan eğitim derslere katılmadığı, \%5,3'ü ise pandemi sürecinde okulu bıraktığı tespit edilmiştir. Bu sonuçlar doğrultusunda; Pandemi süreciyle birlikte hayatımıza yoğun olarak giren uzaktan eğitimin özellikle kız öğrencilerinde etkili ve verimli değerlendirilmesi için araştırmalar artırılmalı, evrim içi derslere devamsızlık Sayfa| 1832 nedenlerinin tespit edilmesi kadar bu devamsızlık durumuna neden olan etkenlerin giderilmesi için programlar yapılmalı ve kız öğrencilerin hem kişisel hem de sosyal uyum durumunu etkileyen faktörlerin belirlenmesi, irdelenmesi ve önlemeye yönelik uygulamaların artırılması gerekmektedir.

EXTENDED ABSTRACT: The new coronavirus disease (Covid-19), which was first detected in December 2019 and spread all over the world, persists as a serious public health problem globally. In addition to being a medical phenomenon, pandemics are a social phenomenon that affects the individual and society at various levels and causes deterioration. As the perceived threat posed by the communicable disease increases, people who experience panic and stress exhibit different behaviors than usual. Most governments around the world have temporarily suspended face-to-face education in educational institutions and switched to distance education to prevent the spread of the Covid-19 pandemic. When we sum up the problems experienced in education during the pandemic, the increase in learning loss and school dropout rates come first. In many regions of our country, especially in Şanlıurfa city, the schooling rate for girls is very low. Therefore, UNICEF emphasizes that girls, among children who are deprived of the right to education, should be given special importance, all children should be given the right to access quality education and that all barriers to girls' right to school and showing success should be eliminated systematically (Adıgüzel, 2013). For this reason, the Covid-19 pandemic and distance education suggests that female 
students are affected more negatively by these negative conditions. In this context, this study was conducted to determine the personal and social harmony levels and dropout status of secondary school female students during the pandemic process. The study used a cross-sectional descriptive design. The population of this cross-sectional descriptive study consisted of female students in 3 rural schools, which are considered to be socially and economically disadvantaged in Şanlıurfa city and placed within the scope of the Girls in ActionCovid Response Team project. No sampling method was used in the study; instead, 94 female students who were reached within the scope of the project and accepted to participate in the study were included in the sample group. The students were reached during the distance education lessons, verbal consent was obtained after they were informed about the study, and the questionnaires were delivered to them through their teachers. The data of this study were collected by using the Hacettepe Personality Inventory (HPI). At the outset, the necessary permission was obtained through an online application from the Scientific Research Platform of the Ministry of Health (2021-03-30T11_56_20.), and ethical permission (Decision No: 24.05.2021/10) was obtained from the Harran University Clinical Research Ethics Committee. The study data were recorded and evaluated on the IBM SPSS Statistics v.22.0 software package. In statistical analyses, continuous variables were represented by mean \pm standard deviation and minimum-maximum values, and nominal variables were represented by counts and percentages. The fit of continuous variables to normal distribution was determined by examining the Sayfa | 1833 Shapiro-Wilk test, normal distribution graphs, and skewness and kurtosis coefficient values together. The significance of the difference in terms of continuous variables was analyzed by independent samples t-test and F-test (One way ANOVA). A p-value below 0.05 was considered significant in all analyses. Of the female students participating in this study, $60.6 \%$ were 12 years old and older, the mean age was $11.96 \pm 1.21$ years. It was observed that $47.9 \%$ of the mothers of the participants were not literate, and $58.5 \%$ of the fathers had primary school or higher education. Also, the families of $58.5 \%$ of the students consisted of 3-8 people, and $57.4 \%$ of them stated that their family income was equal to their expenses. At least a family member of $14.9 \%$ of the students had experienced the Covid-19 disease. Of the students, $59.6 \%$ said they did not attend distance education courses because $54.8 \%$ of those who did not attend said they did not have a tablet, a phone, or a computer, and $31.0 \%$ did not have Internet access. In addition, $5.3 \%$ of the female students stated that they dropped out of school during the pandemic period. It was observed that the mean score of female students from the overall harmony of HPI was 73.91 19.56 , and this score was lower than 80 points, which is the middle point of the $0-160$ score range. Since the mean scores of the students from the social harmony domain (37.13) and personal harmony domain (36.13) were lower than 40 points, which is the middle point of the $0-80$ point range, they were determined to be socially and personally inharmonious. When the students who should be involved in the therapeutic 
mental health practices according to HPI norms and who got 70 points from general harmony, 40 from social harmony, and 30 or less from personal harmony, which corresponded to the 25th percentile, it was observed that female students' mean social harmony scores were at this level. The mean score of the students from all of the sub-dimensions corresponded to the 50th percentile. While the mean score of the students whose mothers were illiterate from the personal harmony domain was 39.2 \pm 9.7 , the mean score of those whose mothers were literate or had more education was calculated as $34.5 \pm 11.0$, and the statistical difference between these variables was found significant $(p<0.05)$. In this study, it was determined that female students who went to middle school during the pandemic were not socially and personally harmonious and that the social harmony levels of the students needed to be included in therapeutic mental health practices. In this study, it was determined that $59.6 \%$ of the female students did not attend distance education classes and that 5.3\% dropped out of school during the pandemic. In line with these results, we recommend that more studies should be carried out for the effective and efficient evaluation of distance education, which has entered our lives intensively with the pandemic, especially for female students, programs should be designed to determine the reasons for absenteeism from online classes and eliminate the factors that cause this absenteeism, and that factors that affect both personal and social harmony of female students should be determined, studied, and practices to prevent them should be increased. 